\title{
NOVOS TEMPOS, NOVOS LUGARES: REFLEXÕES SOBRE A MATERNIDADE EM GRUPOS DE EMPODERAMENTO DE MULHERES
}

\author{
NEW TIMES, NEW PLACES: REFLECTIONS ON MOTHERHOOD WITHIN WOMEN'S \\ EMPOWERMENT GROUPS
TIEMPOS NUEVOS, NUEVOS LUGARES: REFLEXIONES SOBRE LA MATERNIDAD EN GRUPOS DE EMPODERAMIENTO DE MUJERES

\author{
Adriane Rubio Roso* \\ Rosinéia Luiza Gass*
}

\begin{abstract}
RESUMO
Tomando como eixo interpretativo o conceito de gênero, esta pesquisaintervenção objetivou conhecer e analisar as narrativas de um grupo de empoderamento de mulheres, enfocando as representaçóes sociais sobre maternidade. Para análise das narrativas, foi realizada escuta clínica, trabalhando com atenção flutuante. Em seguida, foram feitas inferências e interpretaçôes com base na perspectiva da Psicologia Social Crítica. O grupo se tornou um espaço potencializador para reflexão acerca de subjetividades e das relaçōes de gênero, desenvolvendo discussōes sobre temas relacionados aos lugares das mulheres diante das mudanças sociais e seu impacto no modo de sentir a maternidade. Para além de um espaço de identificação, o grupo possibilitou abrir brechas para transformar representaçôes sociais, colaborando para o processo de fortalecimento e de desejo de mudança nas relaçôes experimentadas pelas mulheres em seus cotidianos.
\end{abstract}

Palavras-chave: Psicologia Social. Representaçōes sociais. Mulheres. Maternidade.

\begin{abstract}
Taking the concept of gender as the interpretative axis, this interventionresearch aimed to identify and analyze the narratives from a women's empowerment group, focusing on social representations of motherhood. Clinical listening with floating attention was applied in the analysis of the narratives. Afterwards, inferences and interpretations were made based on the perspective of Critical Social Psychology. The group became a
\end{abstract}

Texto recebido em 19 de janeiro de 2015 e aprovado para publicação em 19 de setembro de 2016.

"Doutora em Psicologia, professora associada do Programa de Pós-Graduação em Psicologia da Universidade Federal de Santa Maria (UFSM).E-mail: adriane.roso@ufsm.br.

**Especialista em Saúde da Família e Comunidade, psicóloga na Prefeitura de Montenegro-RS, Brasil. E-mail: rosineiagass@gmail. com. 
potentiating field to yield reflections on subjectivity and gender relations, allowing the development of discussions about themes related to women's space in face of social changes and their impact in the way to experience motherhood. Beyond an identification space, the group enabled the opening of opportunities to transform social representations, providing support for the process of empowerment and desire for changes in the relations women go through in their daily lives.

Keywords: Social Psychology. Social representations. Women. Motherhood.

\section{RESUMEN}

Adoptando como eje interpretativo el término de género, esta investigación-intervención tuvo como objetivo conocer y analizar las narraciones de un grupo de empoderamiento de mujeres, enfocando las representaciones sociales acerca de la maternidad. Para análisis de las narraciones, se hizo escucha clínica, trabajando con la atención flotante, y después se hicieron inferencias e interpretaciones a partir de la perspectiva de la Psicología Social Crítica. El grupo se convirtió en un espacio potencializador para reflexiones sobre subjetividades y relaciones de género, desarrollando discusiones acerca de temas relacionados con los lugares de las mujeres ante los cambios sociales y su impacto en el modo de sentir la maternidad. Además de ser un espacio de identificación, el grupo posibilitó vías para transformar representaciones sociales, contribuyendo al proceso de fortalecimiento y al deseo de cambio en las relaciones que experimentan las mujeres en su vida cotidiana.

Palabras clave: Psicología Social. Representaciones sociales. Mujeres. Maternidad.

\section{INTRODUÇÃO}

partirdasegundametadedo séculoXX, presenciamos mudanças econômicas,
sociais e culturais que possibilitaram movimentos de redefinição dos
lugares que homens e mulheres ocupam nos espaços públicos e privados,
modificando os padróes de comportamento no que se refere às relaçóes de
gênero e à sexualidade. Tais movimentos foram influenciados pela ampliação da
liberdade pessoal, modificação dos arranjos de conjugalidade efamília, eliminação
das restriçôes à autonomia das mulheres, ilegalidade da discriminação com base
nas diferenças de gênero e orientação sexual e principalmente pelos estudos
de gênero (Centro Latino Americano em Sexualidade e Direitos Humanos
[CLAM], 2010a, 2010b, 2010c). 
A discussão sobre gênero tem ganhado destaque a partir da ampliação de seu conceito e sua distinção da dimensão biológica do sexo. Ao contrário, gênero se refere à construção social do sexo anatômico, a partir da compreensão de que os modos de subjetivar-se (mulher e homem) são fabricados pelos processos de aprendizado sociocultural, pelos movimentos de relação entre o intersubjetivo, o subjetivo e o transubjetivo e via ação política. Muitas vezes, as relações de gênero não são percebidas como construções sócio-históricas e sim apenas como resultado da decorrência da anatomia dos corpos, dadas a priori como "naturais" ou "instintivas".

Uma das características desse processo de naturalização é centralizar o entendimento acerca de gênero na característica reprodução e conceber a mulher como destinada "naturalmente" à maternidade, o que influencia nas modalidades de inserção no campo social. Por exemplo, durante séculos, estabeleceu-se uma divisão entre o mundo da produção (masculino) e o da reprodução (feminino), restringindo o espaço público aos homens como cidadãos e confinando as mulheres ao mundo doméstico, o que impactou na chamada divisão sexual do trabalho.

Essencializadas, tais compreensões sobre gênero podem gerar desequilíbrios na inserção social e diferenças de valor entre o masculino e o feminino, o que nomeamos de assimetria de gênero. Quando a assimetria é geradora de injustiças sociais e captura dos direitos da pessoa, falamos em iniquidades de gênero ou relações de dominação, que, segundo Thompson (2007), são relações sistematicamente injustas de poder. As relações de dominação, sob o ponto de vista dos estudos de gênero, influenciam significativamente na condição de saúde das mulheres, em especial na esfera da família, do trabalho, da sexualidade e dos direitos sexuais e reprodutivos.

Com base nessa compreensão, desde 2009, vem sendo desenvolvido o projeto de extensão intitulado "Direitos sexuais e reprodutivos: conversando sobre saúde", ${ }^{1}$ dirigido a mulheres maiores de 18 anos que vivem em uma cidade no interior do Rio Grande do Sul, com o objetivo de possibilitar, por meio de grupos de empoderamento (fortalecimento), ${ }^{2}$ um espaço grupal de discussão e reflexão acerca de temas relativos à saúde das mulheres, em especial sobre saúde sexual e reprodutiva, para que, assim, as mulheres se apoiem, sintam-se empoderadas, consigam exercer sua autonomia e batalhem pelos seus direitos e pela sua dignidade. Articulou-se ao projeto de pesquisa denominado "Saúde sexual e reprodutiva: o grupo como dispositivo", 3 que objetivou analisar o dispositivo grupal engendrado a partir do projeto de extensão.

\footnotetext{
1 Projeto registrado no Gabinete de Projetos (GAP) sob o número 024424. Foi contemplado com financiamentos do Ministério da Educação (MEC) (Edital SESu/Proext 2011), FIEX/2010 e FIEX/2011.

2 Sobre a expressão empoderamento, sugerimos a leitura do artigo construído pelo nosso grupo de pesquisa (Roso \& Romanini, 2014).

3 Projeto registrado no GAP sob o número 024424 e contemplado com financiamento do CNPq (Edital Universal 2010).
} 
A proposta de empoderamento ancora-se na Psicologia Social Crítica, cuja categoria central de trabalho é a análise da consciência, e que busca desvelar o aparente e o oculto, sempre percebendo a incompletude e a contradição dos fenômenos sociais (Guareschi \& Biz, 2005), históricos e biopsiquícos. Pelos "grupos de empoderamento", visa-se a ampliar as possibilidades de conscientização, no sentido proposto por Freire (1983), como proposta dialógica que pressupóe a existência de variabilidade e complexidade de saberes, diferenciado de um processo vertical em que alguém tenta convencer o outro de suas ideias. Ao adotar o conceito de conscientização, a Psicologia opera por meio da problematização do cotidiano das pessoas e da intenção de provocar, via questionamento, pequenas rupturas no modo de pensar e representar o mundo e as relações sociais: será que as coisas são assim mesmo? Por que isso acontece? Poderia ser diferente? Como? Essas são questôes iniciais que podem desestabilizar representações, preconceitos e práticas injustas.

O aporte teórico usado para entender o dispositivo grupal foi a teoria das representações sociais (TRS), na sua abordagem processual/dialógica. A finalidade de toda a representação é tornar familiar a não familiaridade, como um sistema de valores, ideias e práticas com dupla função: "fixar" uma ordem que possibilite com que as pessoas se situem no mundo material e social e o controlem; e possibilitar que a comunicação seja possível entre os membros de uma sociedade, fornecendo para esta um código para nomear e classificar, sem ambiguidade, vários aspectos do seu mundo e da sua história individual e social (Moscovici, 1978, 2009).

Nesse sentido, a narrativa grupal nos ajuda a compreender como as pessoas se familiarizam com o(a) Outro(a) nos grupos e relações sociais, ou, dito de outro modo, a compreender por que somos o que somos. Enfim, examinar e compreender

O encontro com o saber de outros pode contribuir para o processo de avaliar criticamente nosso próprio saber, para o desenvolvimento da conscientização e, em última instância, para o empoderamento de uma comunidade em direção a mudanças sociais efetivas (Jovchelovitch, 2008, p. 261).

Nesse momento, apresentaremos parte da pesquisa que se materializou a partir de um dos grupos de mulheres formado na terceira edição do projeto (no ano de 2011). Os grupos vêm ocorrendo de modo aberto e são mediados por 1 psicóloga e 2 estudantes de Psicologia (supervisionadas pela coordenadora do projeto). Os grupos são abertos (entrada de novas participantes no início de cada ano), entretanto, em sua maioria, as participantes têm permanecido desde o início da criação do grupo. O grupo de 2011 foi escolhido intencionalmente para ser apresentado aqui, mas todas as ediçóes têm sido transcritas e analisadas. 
Primeiramente, relataremos o referencial metodológico e teórico que sustentaram a proposta deste trabalho. $\mathrm{Na}$ sequência, a análise da narrativa do grupo de empoderamento estudado, enfatizando um aspecto que frequentemente esteve presente nas falas do grupo: o lugar das mulheres diante das mudanças sociais. Mais especificamente, o que é sentido/vivido por essas mulheres quando falam de seu lugar como mães, já que percebemos que os novos lugares sociais atualmente ocupados pelas mulheres, assim como o acesso cada vez mais facilitado a saberes e informaçōes de diversas áreas de conhecimento, fazem-lhes requestionar o lugar "naturalizado" da maternidade. Para tanto, revisitaremos a própria história da maternidade e das mulheres na família, complementando desta forma a análise.

Em seguida, apresentaremos aspectos transversais em suas vivências: o individualismo do contemporâneo e a sociedade do espetáculo, que produzem subjetividades atravessadas pela angústia da inadequação, inclusive na operacionalidade do exercício da maternidade. Por fim, faremos considerações sobre o dispositivo grupal como instrumento de reflexão sobre os processos histórico-sociais que nos constituem enquanto sujeitos, particularmente como mulheres, e conscientização sobre as razões de sermos o que somos e o que desejamos ser.

\section{MÉTODO}

Por meio de pesquisa qualitativa, buscamos conhecer e analisar as narrativas produzidas em 11 encontros do grupo de empoderamento versão 2011. A pesquisa qualitativa visa a abordar o mundo fora dos laboratórios experimentais e entender, descrever e, às vezes, explicar os fenômenos sociais "de dentro", analisando experiências das pessoas ou grupos, examinando as interações e comunicações entre eles, e a investigação de documentos (Agrosino, 2009). Empregamos a modalidade de pesquisa participante do tipo intervenção (pesquisa-intervenção), que remete à controvertida presença de um pesquisador num campo de investigação formado pela vida cotidiana de indivíduos, grupos, comunidades ou instituiçôes próximos ou distantes, convidados para participarem da investigação como colaboradores (Schmidt, 2008).

Pela prática desnaturalizadora, a pesquisa-intervenção propõe interrogar os múltiplos sentidos cristalizados nas instituições (Rocha \& Aguiar, 2003). Considera a posição ocupada pelo pesquisador nos jogos de poder, fundamentalmente sua implicação com a instituição do saber científico, como também sua abertura para criar zonas que possam favorecer ao coletivo aflorar, que conduzem a invenção e outros modos de expressão. Resulta assim em uma 
coprodução/transformação tanto de quem se propõe a conhecer quanto de quem está sendo conhecido (Paulon \& Romagnoli, 2010).

O grupo que constitui o corpus de análise da pesquisa reuniu-se por um período de aproximadamente um ano, com encontros semanais prefixados em torno de 60 minutos, e cujas temáticas trabalhadas seguiram a linha direcionadora do projeto de extensão, isto é, conversar sobre saúde das mulheres. A divulgação foi feita nas rádios da cidade e jornais, e no mural da Clínica de Estudos e Intervençóes em Psicologia (CEIP) da Universidade Federal de Santa Maria (UFSM). Essa clínica é reconhecida na cidade como um local de atendimento psicológico de adultos, crianças e adolescentes.

Nos encontros analisados, participaram cinco mulheres, que procuraram o grupo após divulgação feita pela equipe coordenadora deste projeto. Antes da entrada no grupo, elas passaram por uma entrevista de triagem individual e foram selecionadas com base nos seguintes critérios: mulheres com idade superior a 18 anos, atendidas na CEIP ou moradoras da cidade em que o projeto se realiza, sem comprometimentos psíquicos graves (sintomas psicóticos), dispostas a participar de atividades em grupo, e que dessem consentimento informado. A maternidade não foi critério para a seleção. $\mathrm{O}$ projeto de pesquisa passou por aprovação do Comitê de Ética, ${ }^{4}$ foi realizada orientação sobre a pesquisa às participantes $\mathrm{e}$ leitura e assinatura do termo de consentimento livre e esclarecido (Resolução do Conselho Nacional de Saúde no 196/1996 \& Resolução do Conselho Federal de Psicologia no 16/2000).

Ao longo do texto, serão utilizadas falas literais que surgiram nos encontros do grupo. Não serão utilizados nomes fictícios para as participantes, pois se pressupõe que cada fala não é produto apenas de uma pessoa e sim que as diversas falas são engendradas pelo dispositivo grupal que se constitui em determinado contexto e tempo, ainda que cada fala se constitua também singularmente. Para a análise das informaçôes, foi empregada escuta clínica, trabalhando com a atenção flutuante para identificar as características dos discursos (variação, detalhes sutis, etc.), os elementos periféricos e as particularidades da argumentação (retórica). Foram feitas inferências e interpretações a propósito dos objetivos previstos. A interpretação do conjunto de informações foi tecida a partir da perspectiva da Psicologia Social Crítica (Strey, 1998; Guareschi \& Biz, 2005; Roso, 2007; Jovchelovitch, 2008) e outros autores que se aproximam das concepções de ser humano e sociedade por tal perspectiva (Badinter, 1985, 2011; Giddens, 1993; Kehl, 2003; Birman, 2000). 


\section{QUESTIONANDO SEU(S) LUGAR(ES): $\quad$ SOBRE REPRESENTAÇŌES DAS MULHERES NA ATUALIDADE}

As experiências de subjetivar-se mulher nos dias atuais apareceram nas narrativas do grupo perpassadas por sentimento de desacomodação quanto às relações de gênero que as caracterizam. Logo nos encontros iniciais, ao expressarem que "A cobrança na mulher, ela tá cada vez maior. [...] Que a gente tá se dando mal, [...] que a gente é cobrada em todos os sentidos", referiam-se às formas como alguns ideais sociais são afetados por diversos acontecimentos. Nesse sentido, o aporte teórico da TRS (Moscovici, 2009) nos auxilia na análise dessas falas, visto que compreende que as representações não são estáticas e nem criadas passivamente, mas são modificadas com base nos acontecimentos sociais e quando passam de um contexto para outro.

A partir da Modernidade, surgiram fatores que ampliaram as possibilidades de atuação das mulheres, entre os quais se destacam a invenção e disseminação da pílula anticoncepcional e de tecnologias de reprodução, novas modalidades de casamento e as lutas em defesa de igualdade de direitos. Entretanto, ainda que surgissem ideais mais amplos e diversificados para as mulheres, estes também se atrelaram àqueles ideais de outrora, como observado na sequência discursiva a seguir:

Tu tem que ser bonita, tu tem que ser inteligente, tu tem que ser magra, tem que ser boa pro teu marido, boa de cama, boa dona de casa, boa de tudo.

Tu tem que ser uma mãe perfeita, teu filho tem que ser educado, tem que ser orientado.

E aí assim, aí fora, que tu tem que lavar bem, passar bem, administrar bem a tua casa.

Ganhar dinheiro.

Tem que estar bem profissionalmente, tu tem que tá bem de vida, teus filhos têm que ser lindos, perfeitos, maravilhosos.

Tua filha tem que tar na faculdade, teu filho tem que tar na faculdade (Entrevistada).

Há uma espécie de renovação desses ideais, ou, como denunciou Badinter (2011), surge um novo "naturalismo" que visa a reconfinar as mulheres não apenas como donas de casa, mas no lugar de "mães perfeitas". Assim, as falas, além de retratarem algumas cobranças sentidas pelas mulheres no momento em que estão em espaços e papéis que por muito tempo lhes foram restringidos, também recolocam novas questôes em relação ao desempenho daqueles que lhes foram atribuídos por décadas, como figuras centrais, como o cuidado com a casa 
e o maternar. Estes últimos são resultantes históricos de determinado período nomeado como a "criação do lar" (Giddens, 1993), a partir do qual o lar passou a ser separado do local de trabalho, o domínio direto do patriarca sobre a família se deslocou e juntamente esse espaço se tornou essencialmente feminilizado, com uma idealização da mulher e "invenção da maternidade".

Esse deslocamento tem efeito nos dias atuais, já que as mulheres sentem que a elas cabe o lugar de "ser administradora do lar", "edifica[dora] [d]o lar", "centro do lar". Tal efeito não é livre de contradições e contestações, pois ao mesmo tempo que esse lugar é percebido por elas como causador de sofrimentos ("Se a mulher não tá bem ou não faz as coisas bem, aí a família inteira não funciona, aí tu tem vontade de te matá"), elas enaltecem o lugar das mulheres no passado, revelado na seguinte intervenção de uma das participantes e que foi endossada pelas demais:

A primeira mulher que queimou o sutiā, às vezes eu digo, que queria que queimassem ela. Porque se tu for pensar nessa independência feminina, não, é sério, pensa, o pensamento assim, como é que vou dizer, assim, é seco, sem olhar as arestas assim, tu vai pensar assim, queimô o sutiã e quis trabalhá. Antigamente, a mulher cuidava da casa e dos filhos, tudo os filhos eram bem-educado, não tinha problema [...]. Daí o que aconteceu, foi trabalhar fora, a mulher... exatamente isso. Tem que ser magra, tem que ser bonita, tem mulher, tem que ser mãe, tem que ser amante, inteligente, tem que ser bem-sucedida na vida, tem que ganhar bastante dinheiro, tem que andar de carro novo e assim vai indo. Tu tem que ser. Antigamente o que a mulher era, a mulher era nada mais que mulher (Entrevistada).

A caracterização da fala "a mulher era nada mais que mulher" apareceu atrelada ao desempenho unicamente do cuidado do lar e da educação dos filhos, ao encontro da representação de que antigamente a mulher era nada mais que mãe. Conduz à reflexão de que, embora hoje possamos dizer que conquistamos espaços para além dos nossos lares, ainda dentro destes, as responsabilidades continuam sendo prioritariamente atribuídas à figura das mulheres (Strey, 2011), muitas vezes sobrecarregando-as e conduzindo a novas modalidades de assimetrias de gênero, ao produzir discursos de pedido de retorno delas aos lares. Desse modo, podemos entender que as representações sociais são práticas em ação, em movimento, como se fossem um elástico ora esticado, ora solto, num perpétuo questionamento do que se quer para nossas vidas.

Uma das participantes relatou que, antes da própria maternidade, tinha uma "visão muito romântica do ser mãe, de gestação e de parto e depois do 'ser mãe". Verbalizou que tal idealização não se concretizou como o imaginado e que enfrentava um sofrimento em estar no papel materno: "Eu amo os meus filhos profundamente, mas eles não são a minha vida, eles não são tudo pra mim, sabe? [...] Eles, na verdade, são uma grande responsabilidade [...]. É muito difícil, tu nunca sabe quando tu tá acertando, quando tu tá errando”. 
Outra participante contribuiu com o relato de que nunca teve uma visão romântica sobre gravidez. Para ela, a gravidez foi "horrível, pois não tem nada de glamour, tua barriga começa a aumentar, tuas pernas começam a doer, tuas costa... Não teve nada bom".

Tais sequências comunicativas indicam que, se o ideal materno, produto da feminilização do lar, produz o enaltecimento de aspectos bons atrelados à maternidade e, por vezes, o ensurdecimento de outros tantos aspectos relativos a tal papel, pode conduzir a sentimentos como referidos pelas mulheres de estar "fora desse contexto" da "plenitude da maternidade". A participante exemplifica esse ensurdecimento ao falar que as pessoas não percebem a diferença de seus sentimentos em relação ao "ser mãe" e que, para evitar o "olhar do outro", prefere não tocar no assunto "maternidade". Ao mesmo tempo que percebe e questiona que os pontos negativos acerca da maternidade não são debatidos em nossa sociedade, acredita que se conseguisse sentir a maternidade de outra maneira (mais próxima da "plenitude materna"), a sua "vida, hoje, estaria fluindo muito melhor também”.

Esses apontamentos, a nosso ver, refletem a angústia da inadequação, pois é como se um pedaço de si precisasse ceder lugar para a mulher caber inteira numa parte só. A tendência discursiva é dicotomizar os acontecimentos e sentimentos, e vivermos como se um lado fosse incompatível e separado de outro. A contradição entre questionar a norma e, ao mesmo tempo, buscar alcançá-la aponta para o quão complexo é a construção de nossa subjetividade e de gênero, realizada com base em processos histórico-sociais, alguns identificados pelas participantes:

É que a gente é educado desde pequenininho, eu tenho horror disso. A gente é educado com a boneca na... Hoje em dia, também eu olho uma criança com uma boneca, me dá uma coisa também. Eu digo: por que a gente tem que ser educado com filho no colo? Com bonequinha e coisa, e o homem com carro.

Hoje, aos poucos, isso tá mudando. Mas anos atrás, a mulher, pra ser [...] Ela tinha que ser mãe. E, aliás, se tu ver, tem até propagandas e coisa que fala "a mulher só se completa quando é mãe, a mulher só se não sei o quê, ser sublime quando é mãe, a maternidade não sei o que não sei o quê". Isso é uma enorme duma mentira, e isso é implantado na cabeça das meninas! (Entrevistada).

Apesar de sinalizarem que os comportamentos esperados para cada gênero são construídos ao longo de nossa socialização, a referência das diferenças de gênero definidas com base no biológico também permaneceu em suas falas:

Aquela coisa: mulher cuida as crianças. Até pela nossa visão periférica ser maior que a dos homens. Eu acho que é muito instinto [...]. E isso, desde antes de ela sofrer influência da escolinha, porque, em casa, a gente tenta ser neutro, não puxar muito por um lado ou por 
outro. E nós mostramos pra ela as possibilidades, ela que escolhe tudo, os brinquedos, ela sempre ganha brinquedo de menino e de menina. Tudo igual, tudo, e ela sempre preferiu. Então eu acho que tem uma parte instintiva também, que influencia (Entrevistada).

Esse recorte que toma a maternidade pelo viés biológico, como instinto materno, pode nos levar pelo menos por dois caminhos. Um deles é considerar que a sexualidade é vivida como exclusivamente biológica, e sua finalidade é a procriação. O segundo caminho se refere a classificarmos aquelas mulheres que não desejam ter filhos ou que não relatam esse "amor incondicional" como anormais. Ambos conduzem a considerarmos as mulheres como as principais (se não únicas) responsáveis pela educação de seus filhos e a diminuir a responsabilização dos homens diante de tal função.

Badinter (1985) questiona essa valorização da maternidade e os problemas de a definirmos em termos de instinto, apontando que, anteriormente ao século XVIII, a infância não tinha nenhum valor e, inclusive, houve práticas disseminadas em quase todas as esferas sociais nas quais as mães abandonavam seus filhos para estes morarem em casas distantes, junto a amas de criação. Além disso, indaga o fato de que, se consideramos a ideia de amor como natural, como poderia esse amor se voltar mais para um filho do que para outro.

Até aqui vimos que as mulheres, cujo papel por muito tempo foi restrito ao desempenho do "ser mãe", têm ocupado novos lugares sociais, podem fazer outras escolhas e ter outras vivências. Porém percebemos que ainda somos educados e socializados com base nas divisões que colocam a mulher como figura principal no desempenho dos cuidados do lar e filhos, e que, quando elas desempenham outros papéis (que, à primeira vista, não estão relacionados à maternidade), estes também produzem questionamentos em relação ao "ser mãe".

As narrativas possibilitaram observar diversas experiências de uma mesma experiência do maternar: a produção de confrontos entre o ideal da maternidade e o real, e a percepção dos processos de socialização/construção de relações de gênero que coloca a maternidade como uma norma, e, em contraponto, a referência ao biológico como constituidor das relações de gênero e os desejos das mesmas mães que questionam a norma de também fazerem parte dela. Dessa forma, ainda que haja produção de questionamentos em relação ao que está naturalizado sobre a maternidade, sentimentos de angústia, culpa e ansiedade se misturam a essa experiência e constringem, por vezes, o viver bem dessas mulheres.

Estes sentimentos, além de estarem intimamente relacionados aos produtos da invenção da maternidade (Giddens, 1993), conectam-se ao sentimento de inadequação no contexto da Pós-Modernidade. Nesse sentido, torna-se 
interessante um aprofundamento acerca de formações subjetivas contemporâneas, especialmente em relação à infância, temática que será apresentada no próximo segmento.

\section{DA INVENÇÃO DA MATERNIDADE AO CULTO À CRIANÇA}

As experiências narradas dão fortes indícios de que o sentimento de culpa em relação ao desempenho do papel materno está acompanhado de sentimento de inadequação, atrelada à disponibilidade de informações sobre o desenvolvimento das crianças, criação/educação de filhos e a dificuldade de colocá-las em prática. Cada vez mais informações desse tipo, originadas de disciplinas como Medicina, Enfermagem, Psicologia, etc., estão acessíveis à população e são apropriadas pelo Estado para definir suas políticas públicas, pelas escolas para lidarem com os pais e seus alunos, pelas mídias para veicularem seus programas e, consequentemente, pelas próprias famílias para lidarem com sua prole. Todas, de uma forma ou outra, fabricam as subjetividades das mulheres.

Por exemplo, mesmo diante do estranhamento quanto à amamentação ("Parecia um bichinho me sugando"), as informações legitimadas pelo saber científico se fizeram valer na vivência de uma das mulheres, que amamentou "porque é o certo, porque depois ela vai ter menos problemas na... durante a vida dela, né, vai ajudar na imunidade... tarará..., aquela coisa da informação”. Para outra participante, as próprias informaçōes que eram apresentadas como verdades a respeito de gravidez, maternidade e desenvolvimento infantil aumentaram seu sofrimento e sentimento de inadequação: "Acho que isso mais me atrapalhou ainda, porque eu não consegui colocar nada daquilo em prática, daí eu me senti culpada porque não consegui colocar aquilo que é o CORRETO [acentuando a voz] em prática”.

Se por um lado, as "verdades" científicas circulam em nossos cotidianos, por outro, há a possibilidade de (re)construção dessas mesmas verdades por meio do grupo, pois

As pessoas analisam, comentam, formulam "filosofias" espontâneas, não oficiais, que têm um impacto decisivo em suas relaçôes sociais, em suas escolhas, na maneira como eles educam seus filhos, como planejam seu futuro, etc. Os acontecimentos, as ciências e as ideologias apenas lhes fornecem o "alimento para o pensamento" (Moscovici, 2009, p. 4).

Em meio a tantas informações "científicas" e consensuais, produzindo antinomias sobre o que fazer/não fazer, essas mulheres expressaram que ser mãe em tempos atuais as conduzem a um dilema de ordem ética, que provoca tensão e reforça a culpa delas. A própria influência que receberam de sua família 
de origem, quando comparada à educação que dão ou gostariam de dar a seus filhos, reforça algumas antinomias: "Mas será que a mãe não fez certo e eu tô fazendo errado de dar, tentá conversar? [...] cada vez que a gente bate de frente com uma coisa assim, tu não sabe se realmente tu tá fazendo a melhor coisa, se eu devia fazer como minha mãe fazia".

Uma participante relatou desconforto ao pensar que, apesar de seu esforço para passar uma imagem de "boa mãe", futuramente seus filhos poderiam criticar a educação que receberam dela, assim como ela faz críticas à educação que recebeu de sua própria mãe:

Daí tu pensa "meu Deus do céu, que eu sou igualzinha", e aí a gente cobra, porque tu também não quer passar aquela impressão... Porque não é aquilo daquela maneira que eu entendi. Como eu recebi a mensagem da minha mãe, EU NÂO QUERO [acentuando] que os meus filhos recebam da mesma maneira, porque, na verdade, não é aquilo que eu entendi que eu tô falando, sabe? Ah, tá loco! (Entrevistada).

Como uma compulsão, repetimos com nossos filhos muitos dos traços característicos da educação que recebemos de nossos pais, mesmo que talvez tenhamos jurado, quando adolescentes, que não os repetiríamos. Mas o problema não parece residir na repetição somente, mas na evocação da culpa por repetir, que, na Pós-Modernidade, fabrica a subjetividade vinculada a certo modo-mãemulher. Juntamente a isso, está presente na sociedade atual a monumentalização da infância, que produz um modo-filho(a), o qual interage dialeticamente com o modo-mãe-mulher.

Em relação à monumentação da infância, Monti (2008) desenvolve uma reflexão importante ao considerar características da cultura ocidental. Defende que, antigamente, as renúncias que eram necessárias às crianças são diferentes das atuais, pois hoje "A renúncia às próprias aspirações não é sentida como uma necessidade inevitável, e sim como um ataque injustificado à liberdade e aos direitos do indivíduo" (Monti, 2008, p. 245).

O autor sinaliza que, nas sociedades ditas avançadas, desenvolveu-se um verdadeiro culto à infância que pressiona os pais desde antes do nascimento e que, na clínica, não é raro encontrar filhos que exercem sobre seus pais um poder quase sádico. A fala a seguir ilustra a monumentalização da infância na Contemporaneidade:

Chamaram na escolinha dela porque ela era muito hiperativa. Ela trocô de turminha, ela era do X [nome da escola], onde eles tinham poucas atividades, e era mais brincadeira, daí agora ela passou pro Y, ficou mais formal a educação! Então, JOGARAM [acentuando o tom de voz] um monte de aulinha nela, teatro, música, dança, educação física, informática, balé, inglês, e daí nós também colocamos ela em inglês. Então tinha mais ali pra ela ir. Eu 
acho que foi muita coisa, e aí ela tava REBELDE [acentuando o tom novamente] demais. Daí, eles me chamaram porque ela não queria fazer nada, ela não aceitava fazê nada que os professores mandavam. [...]. TH, é aquele da hiperatividade (Entrevistada).

A fala indica que, na subjetividade e no comportamento da criança, atravessavam ideais de desempenho em uma série de atividades, e porque esta não as desempenhou como o esperado, e assim não gratificou aqueles que as propuseram [aqueles que "jogaram" tais atividades], recaiu sobre ela dúvidas e até mesmo hipóteses do por que "fracassou". Tal situação concorda com o aspecto assinalado por Monti (2008), que defende que a sociedade ocidental já não se reconhece numa cultura da culpa e do conflito, mas a angústia da culpa foi substituída pela ANGÚSTIA DA INADEQUAÇÃO (grifo nosso), do vazio, do déficit de desempenho, da insuficiência.

Diante disso, os adultos foram em busca de um terceiro que pudesse contribuir na compreensão do que ocorria naquele momento. A criança foi levada até um profissional de Psicologia, que apontou algumas necessidades de mudança na forma da educação que os pais ofertavam à criança, o que gerou a eles um alívio em sua preocupação acerca do comportamento da criança, como também os conduziu a um processo de reavaliação de seus próprios modos de agir, como nos mostra a próxima sequência:

Aí eu achei que pudesse ser isso [hiperatividade]. A preocupação, mas não é, é SÓ [acentuando] falta de limites mesmo, que nós temos que impor, eu e o pai dela. A gente não... a gente não, eu achava, pra mim tava tudo bom, achava que a educação dela tava ótima e, na verdade, não tava. E ela demonstrou isso na escolinha. Aí nós estamos sendo mais firmes com ela. Corrigimos alguns pontos, a gente fazia muita chantagem com ela, posso fazer uma coisa que tu vai ganhar uma bala. [...] tudo assim, ou tu vai assisti tal filme, se tu quiser, tudo na base da chantagem, e agora nós paramos com isso. No início, foi meio turbulento, mas agora ela tá aceitando, ela tem que fazê independente de ganhá alguma coisa. Ela tem que saber que aquilo é uma obrigação dela, então (Entrevistada).

Tal relação sustentava-se num modelo de condicionamento operante: eu dou (uma bala, um filme etc.) se você faz o que mando. Também o lugar de trono à criança fica claramente estabelecido: para esta proporcionar algo aos pais, é só a base de um valor-capital e não do valor-mores (costumes). A mudança nesse relacionamento pais-filha, inicialmente difícil, proporcionou que, aos poucos, os papéis majestade-súditos se modificassem também.

É importante ressaltar, com base no exemplo, que algo do espaço público, o que se apresentou na escola, proporcionou que fossem revistas algumas questóes de uma ordem mais íntima e privada da família. Mas na mesma medida em que se revê o que é de ordem privada, se revê o público também, pois ambos se conectam, relação essa que foi aprofundada pelas participantes no grupo. 
Segundo algumas, estar no espaço público com seus filhos é considerado difícil, pois se sentem sob o olhar vigiador de um outro que estabelece um ideal de mãe, ideal de educação, etc. Citam como exemplo idas ao mercado, espaço no qual os filhos podem apresentar comportamentos, como chorar, reclamar, solicitar o que não está de acordo com o que elas mesmas acham adequado e necessário. Nessas circunstâncias, percebem que as pessoas que estão próximas, os expectadores, produzem discursos e opiniōes a respeito do modo como elas deveriam agir com os filhos, assim como momentos de constrangimento e indecisão: "Agora educo, cheio de gente, ela berrando... Ou dou pra, acalmar a situação", "É horrível, porque tu tem a sensação que realmente tu falhou, tu não conseguiu e aí todo mundo te olha”. Novamente o sentimento de inadequação.

Outras estratégias são utilizadas pelas mulheres do grupo para evitar a sensação de constrangimento em público, como não levar os filhos a esses lugares:

Não levo no mercado, não levo em lugar nenhum. Ou quando eu vou levar eu converso em casa com ela antes.

Eu tô sempre aqui arquitetando, sabe... Como é que vai ser a minha rotina com ela? Ah, tal hora eu vou levar em tal lugar, vou falar isso... Dá um cansaço! (Entrevistada).

Em todas essas impressões verbalizadas pelas participantes, estão presentes aspectos intensificados pela cultura ocidental contemporânea, que segundo Birman (2000), constituem uma nova cartografia do social resultante da tradição do individualismo iniciada no século XVIII, e na qual o eu se encontra situado em posição privilegiada. Para ele, essa cultura do narcisismo e da sociedade do espetáculo gera novas formas de subjetivação, na qual os destinos do desejo assumem uma direção marcadamente exibicionista e autocentrada, em que há dificuldade para descentrar de si mesmo, e o horizonte intersubjetivo se encontra esvaziado e desinvestido das trocas inter-humana.

Implica uma crescente volatização da solidariedade: "A solidariedade seria, assim, o correlato de relações inter-humanas fundamentadas na alteridade. Para isso, no entanto, seria necessário que o sujeito reconhecesse o outro na diferença e singularidade, atributos da alteridade" (Birman, 2000, p. 25, grifo das autoras). Fala-nos que o eu se transforma numa majestade permanente, iluminado que é o tempo todo no palco da cena social, e ressalta que a psicopatologia da PósModernidade é sempre o fracasso do indivíduo em realizar a glorificação do eu e a estetização da existência, ou seja, no fracasso da participação do sujeito nessa nova ordem social.

Tais processos subjetivos são próximos àqueles observados por Monti (2008) em ambulatórios e consultórios, nos quais há uma grande quantidade de 
pacientes que chegam com queixas genericamente "depressivas" e vazias, sintomas de perda de identidade e solidão (queixas similares a muitas das mulheres que chegaram até nós com o intuito de participar dos grupos), com dificuldade de gostar de si mesmos e um sentimento de inveja em relação às outras pessoas que se presume que desfrutem disso tudo. Para o autor, tais pessoas estariam fechadas em uma espécie de trono-armadilha (Monti, 2008), já que ser uma majestade permanente resulta em dificuldades para reconhecer o outro em sua diferença, pois se está preso a olhar somente a si, assim como dificulta reconhecer a sua própria alteridade. $\mathrm{O}$ que se percebe é um sofrimento sem sofrimento.

Apesar de esses "olhares" desconfortarem as participantes e, ao longo dos encontros grupais, perceberem que o fracasso é uma construção social que não leva em conta as diferenças, ou que o social as pressiona de tal forma que produz a sensação de estarem sempre à beira do fracasso, independente da escolha e contexto ("Agora educo, né, cheio de gente, ela berrando... Ou dou pra acalmar a situação"), ainda assim, mostraram indicativos de desejarem o enaltecimento nessa mesma cena social. Por vezes, desconfortadas com o social, por outras, desconfortadas com elas próprias.

O interessante é que a relação ambivalente das participantes com o maternar aparentemente não interfere no desejo de seus próprios filhos decidirem ter ou não filhos futuramente. Entretanto há um reflexo sobre o desejo de casar, ou melhor, sobre o não desejo de casar desses filhos, como ilustra a fala seguinte: "A minha filha olha pra mim e diz: 'Eu quero ter dois filhos, assim que nem tu'. [...] 'Eu quero ter um casal, mas eu não vou casar, eu não quero ter marido, eu só quero ter dois filhos"”.

Vale questionar o que significa querer ter filhos, mas não querer casar? $\mathrm{O}$ que está a mudar aí em termos de configuraçōes de relações de gênero? Esse diálogo entre mãe e filha ilustra posições de duas geraçôes distintas: uma que, embora casada, viveu/vive uma maternidade mais "solitária" (sem participação efetiva do pai nos cuidados integrais da criança) e outra que foi/é testemunha dessa maternidade circundada pela angústia da inadequação. Se aumentou o número de mulheres que não quer ter filhos, como pontuou Badinter (2011) no contexto francês, aqui parece que o desejo de se tornar mãe permanece; o que muda é o desejo de casar-se.

Kehl (2003) contribui com tal debate, ao relatar que uma das queixas que os psicanalistas mais escutam em seus consultórios é um desconforto com as configuraçôes familiares atuais, exemplificados em pedidos como "Eu queria tanto ter uma família normal!". Para a autora, em tais falas, paira um discurso institucional acerca das novas configurações familiares, cujos enunciados podem 
ser juristas, pedagogos, religiosos, psicológicos, midiáticos, os quais relacionam e, ou, responsabilizam a "dissolução da família" pelo quadro de degradação social em que vivemos (delinquência juvenil, a violência, as drogadiçôes, a desorientação dos jovens, etc.).

A autora questiona a legitimidade desses discursos, indicando que podemos estar nos esquecendo dos custos que esse "ideal" de família/modelos familiares acarretam. Por exemplo, projetamos nostalgicamente um sentimento de conforto e segurança na "tradicional família brasileira", "hierárquica" e organizada em torno do poder patriarcal, esquecendo a que custo (psíquico, sexual, emocional) ela se manteve, a um só tempo protegidas e oprimidas pelo patriarca da casa grande. Ademais, constata que o peso da dívida para com a família "ideal”, no caso, patriarcal, pode impedir os adultos de legitimar suas funções e sustentar sua posição de autoridade responsável perante as crianças, no âmbito das estruturas familiares que eles foram capazes de constituir. Por fim, ressalta a necessidade de que o espaço público seja revalorizado e as responsabilidades públicas retomadas, sobretudo no Brasil, pois a família sozinha, independentemente de qual seu modelo de configuração, não será capaz de dar conta da crise ética que estamos enfrentando.

Dando continuidade ao raciocínio de Kehl (2003), podemos cogitar que as novas gerações, ao presenciarem a inadequação por parte das mães, estão imaginando modos de viver a maternidade de outra maneira. Mas seria essa outra maneira propiciadora de uma singularidade que produzirá uma boa vida? Não temos respostas a essa questão, mas sabemos que, na geração das mães que participaram do grupo, há um desejo de retorno ao status quo anterior, dito de outro modo, um retorno aos modelos de família tradicional, justamente aquele que elas mesmas criticaram: "Antigamente, a mulher cuidava da casa e dos filhos, tudo. Os filhos eram bem-educados, não tinha problema”. Mas a crítica é o primeiro passo para mudanças. Talvez, no processo de repensar a maternidade e viver contradiçôes, ancoradas nas experiências de "antigamente", possamos encontrar não o mesmo, mas novos modos de maternar e representar a maternidade que propiciem uma vida melhor e mais equânime a todos.

\section{CONSIDERAÇÕES FINAIS}

O grupo se mostrou um espaço potencializador para reflexôes acerca de subjetividades e gênero diante das mudanças que ocorreram para as mulheres no contexto social mais amplo, pois a saída delas para o espaço público tem aberto um leque de possibilidades para suas existências que, para a maioria delas, fora, até então, restrito ao papel materno. Mas se percebe que, juntamente ao 
contexto histórico-social atual, tais conquistas relançam questionamentos acerca da maternidade por novos ângulos.

Surgem questões contraditórias em relação aos diversos lugares que as mulheres podem ocupar, pois os espaços se abrem, mas, muitas vezes, não se proporcionam as condições culturais, sociais e políticas às mulheres para refletirem e questionarem sobre as posições que ocupam no mundo e sobre que posição desejam construir. Aliam-se a tal aspecto as características do cenário atual, cuja cosmovisão leva à luta desenfreada para vencermos o outro, para a competição, para uma sociedade do espetáculo e narcisismo, que desconsidera a alteridade e que impacta o próprio modo de sentir e fazer a maternidade e as relações de gênero.

O grupo operou como um dispositivo de singularização ao possibilitar o acolhimento e construção de representações múltiplas, incluindo suas contradiçôes. Constituiu-se, desse modo, como um locus de questionamento das representações sociais que construímos e que mantêm as inequidades de gênero, a partir das nossas interaçôes, de nossas tradições e costumes, como também dos discursos legitimitados como verdades que chegam até nós cada vez com maior intensidade. O dispositivo grupal colaborou para o processo de conscientização, de fortalecimento e de disparo de desejos de mudança nas relações experimentadas no cotidiano.

Por fim, podemos dizer que as narrativas produzidas a partir de um dispositivo grupal nos mostram o quanto plásticas são as representações sociais da maternidade e que a heterogeneidade destas é justamente o que faz movimentar o tornarse mãe e mulher, e consequentemente suas representações sociais. Embora esta plasticidade ainda não possibilite que as relações de gênero sejam de fato justas, a passos lentos, de forma não linear e com contradições, vamos transformando um campo representacional histórico. Com a abertura para o diálogo entre mulheres sobre os tensionamentos do cotidiano, vamos inventando modos de singularizar-se mulher. 


\section{REFERÊNCIAS}

Agrosino, M. (2009). Etnografia e observação participante. Porto Alegre: Artmed. (Coleção Pesquisa Qualitativa).

Badinter, E. (1985). Um amor conquistado: o mito do amor materno. (5a ed.). Rio de Janeiro: Nova Fronteira.

Badinter, E. (2011). O conflito: a mulher e a mãe. Rio de Janeiro: Record.

Birman, J. (2000). Mal-estar na atualidade: a psicanálise e as novas formas de subjetivação (8a ed.). Rio de Janeiro: Civilização Brasileira.

Centro Latino Americano em Sexualidade e Direitos Humanos. (2010a). A construção social do gênero (vol. 2). Rio de Janeiro: CLAM, Universidade Estadual do Rio de Janeiro; Brasília: Secretaria de Políticas para as Mulheres, Presidência da República.

Centro Latino Americano em Sexualidade e Direitos Humanos. (2010b). Gênero: conceito importante para o conhecimento do mundo social (vol. 1). Rio de Janeiro: CLAM, Universidade Estadual do Rio de Janeiro; Brasília: Secretaria de Políticas para as Mulheres, Presidência da República.

Centro Latino Americano em Sexualidade e Direitos Humanos. (2010c). Gênero, sexualidades e desigualdades (vol. 3). Rio de Janeiro: CLAM, Universidade Estadual do Rio de Janeiro; Brasília: Secretaria de Políticas para as Mulheres, Presidência da República.

Freire, P. (1983). Pedagogia do oprimido (16a ed.). Rio de Janeiro: Paz e Terra.

Giddens, A. (1993). A transformação da intimidade: sexualidade, amor \& erotismo nas sociedades modernas. M. Lopes (Trad.). São Paulo: Editora da Universidade Estadual Paulista.

Guareschi, P. \& Biz, O. (Orgs.) (2005). Midia \& democracia. Porto Alegre: Evangraf.

Jovchelovitch, S. (2008). Contextos do saber: representaçôes, comunidade e cultura. Petrópolis: Vozes.

Kehl, M. R. (2003). Em defesa da família tentacular. Fronteiras do Pensamento. Recuperado a partir de https:/www.fronteiras.com/artigos/maria-rita-kehlem-defesa-da-familia-tentacular 
Monti, M. R. (2008, junho). Contrato narcisista e clínica do vazio. R. Barni (Trad.). Revista Latinoamericana de Psicopatologia Fundamental, 11(2), 239253. Recuperado a partir de http://www.scielo.br/scielo.php?script=sci_ arttext\&pid=S141547142008000200006

Moscovici, S. (1978). A representação social da psicanálise. Rio de Janeiro: Zahar.

Moscovici, S. (2009) Representaçôes sociais: investigaçôes em Psicologia Social. Petrópolis: Vozes.

Paulon, S. M. \& Romagnoli, R. C. (2010, janeiro-abril). Pesquisa-intervenção e cartografia: melindres e meandros metodológicos. Estudos e Pesquisa em Psicologia (UERJ), 10(1), 85-102. Recuperado a partir de http://www.revispsi. uerj.br/v10n1/artigos/pdf/v10n1a07.pdf

Resolução Conselho Federal de Psicologia no 16, de 20 de dezembro de 2000. (2000, 20 dezembro). Dispõe sobre a realização de pesquisa em Psicologia com seres humanos. Brasília: CFP.

Resolução Conselho Nacional de Saúde no 196, de 10 de outubro de 1996. (1996, 10 outubro). Aprova as diretrizes e normas regulamentadoras de pesquisas envolvendo seres humanos. Brasília: CNS.

Rocha, K. F.de. \& Aguiar, M. L. de (2003, dezembro). Pesquisa-intervenção e a produção de novas análises. Revista Psicologia: Ciência e Profissão, 23(4), 6473. Recuperado a partir de http://pepsic.bvsalud.org/scielo.php?pid=S141498932003000400010\&script=sci_arttext

Roso, A. (2007). O cotidiano no campo da saúde: ética e responsabilidade social. In M. V. Veronese \& P. A. Guareschi (Orgs.), Psicologia do cotidiano: representações sociais em ação. (pp. 119-145). Petrópolis: Vozes.

Roso, A. \& Romanini, M. (2014). Empoderamento individual, empoderamento comunitário e conscientização: um ensaio teórico. Psicologia e Saber Social, 3, 83-95. Recuperado a partir de https://doi.org/10.12957/psi.saber. soc. 2014.12203

Schmidt, M. L. S. (2008). Pesquisa participante e formação ética do pesquisador. Revista Psicologia Ciência e Saúde, 13 (2), 391-398. Recuperado a partir de http://www.scielosp.org/scielo.php?script=sci_ arttext\&pid=S1413-81232008000200014 
Strey, M. N. (1998). Gênero. In M. da G. C. Jacques \& M. N. Strey (Orgs.), Psicologia Social contemporânea: livro-texto. (pp. 181-198). Petrópolis: Vozes.

Strey, M. N. (2011, outubro). Mulheres. Palestra realizada na IX Semana Acadêmica da Psicologia da Universidade Federal de Santa Maria: a prática da Psicologia no combate às opressões das minorias sociais.

Thompson, J. B. (2007). Ideologia e cultura moderna: teoria social critica na era dos meios de comunicação de massa. Petrópolis: Vozes. 